\title{
Umberto Eco and the Aesthetics of Vagueness
}

Rocco Monti

\section{(2) OpenEdition}

\section{Journals}

Electronic version

URL: http://journals.openedition.org/ejpap/2306

DOI: 10.4000/ejpap.2306

ISSN: 2036-4091

\section{Publisher}

Associazione Pragma

Electronic reference

Rocco Monti, "Umberto Eco and the Aesthetics of Vagueness", European Journal of Pragmatism and American Philosophy [Online], XIII-1 | 2021, Online since 02 April 2021, connection on 04 April 2021. URL: http://journals.openedition.org/ejpap/2306 ; DOI: https://doi.org/10.4000/ejpap.2306

This text was automatically generated on 4 April 2021.

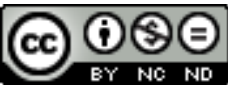

Author retains copyright and grants the European Journal of Pragmatism and American Philosophy right of first publication with the work simultaneously licensed under a Creative Commons Attribution-

NonCommercial-NoDerivatives 4.0 International License. 


\title{
Umberto Eco and the Aesthetics of Vagueness
}

\author{
Rocco Monti
}

\section{AUTHOR'S NOTE}

I want to thank both anonymous referees for their insightful criticism and comments and for suggesting many corrections and additions. I want to thank Rossella Fabbrichesi and Tullio Viola for the help they gave me. I also want to thank Stefano Bacin for his continuous support.

The evolution of forms begins or, at any rate, has for an early stage of it, a vague potentiality... It must be by a contraction of the vagueness of that potentiality of everything in general, but of nothing in particular, that the world of forms comes about. (C.S. Peirce CP.6.196)

\section{Introduction}

1 At the beginning of his studies in aesthetics, Eco found in Dewey's Art as Experience and in Luigi Pareyson's aesthetics an approach to think about art and artwork in a nonidealistic way. ${ }^{1}$ According to Eco "Croce's idealistic philosophy defined art as the intuition of a feeling, thereby clearly implying that it had nothing to do with either morality or knowledge" (Eco 1989: 158), whereas Pareyson put at the core of his investigations the specificity of the person, the interpretative perspective and the active force of forms. I will deal with the concepts of formativity and interpretation as they are formulated by Pareyson in Estetica: Teoria della Formatività shortly (see section 3); here lies indeed the proximity and the distance between Eco's and Pareyson's 
perspectives. Presently, though, I would like to consider the central intentions of Eco's Opera Aperta.

The subtitle of this book, Form and Indeterminacy in Contemporary Poetics, which is missing in the English version, exemplifies Eco's intentions and purposes. As stated by David Robert in the introduction to the English edition of the book, "Opera Aperta is a polemic book, in marked conflict with the Crocean aesthetics that dominated the Italian academic world in the early sixties" and "Opera Aperta arose partly out of Eco's work on general questions of aesthetics, which was strongly influenced by the antiCrocean, though still idealist, philosophy of his mentor at the University of Turin, Luigi Pareyson" (Eco 1989: viii-ix). Although this book has a declared enemy - the aesthetics of Benedetto Croce - it must be said that Opera Aperta explains and justifies the apparently radical differences between modern and traditional art. The term operathe work of art - is defined by Eco as "an object endowed with structural properties that render possible a number of successive interpretations, a series of evolving perspectives, but that also enable us to coordinate such a series" (De Mallac 1971: 32).

Opera Aperta aims to identify those works of art that make openness their formal characteristic par excellence. As we shall see in this essay, from the concept of openness, which goes hand in hand with that of vagueness, it does not follow that these forms of contemporary art abandon the formal aspect in favor of amorphous indeterminacy; what Eco calls open work does not deny the formal aspect as such but reformulates and redefines it in a dynamic way. In this text Eco undertakes to write a sort of geometry of open works of art: he dwells on different forms of art, from the music of Karlheinz Stockhausen and Luciano Berio, to reflections on comedians, on poets and novelists like Stéphane Mallarmé, James Joyce and Dante, passing through a detailed analysis of cinema and its practices, from the camera as an interpretative perspective to the study of visual works of art.

If we were to synthesize the object of this research, we could refer to a notion now acquired by many contemporary aesthetics: the work of art is a message fundamentally ambiguous, a plurality of meanings living together in one signifier.

(Eco 1962: 16; my translation)

Needless to say, the concept of open work will be the fil rouge in this paper, albeit in the fifth section it seemed useful to consider other writings by Eco as well, since the concepts of openness and vagueness run like a subterranean river in his thought, especially with reference to the open form of narrative and poetic texts. Thus, we will not deal with all forms of contemporary poetics but only with the narrative one.

This paper neither gives a complete interpretation of Eco's semiotics, nor tries to write a sort of historical genealogy of his thought, encompassing Peirce, Dewey and Pareyson. Mainly, it takes certain features of his thought as points of departure in order to reconstruct them in terms of a pragmatist aesthetics, accepting not only the existence but also the value of indeterminacy and vagueness. In the course of this paper, I would like to give three main explanations for the reason why the aesthetics of the open work is an example of pragmatist aesthetics. Firstly, according to Eco, art is neither "an ethereal thing" nor something purely spiritual but, rather, an embodied way to express, articulate and fulfill our interaction with natural and cultural contexts. Secondly, Eco has a democratic vision of art: this aspect of the aesthetics of the open work can be found in the rehabilitation of popular forms of art, in sharp contrast both with Croce's idealistic theory of art and with Pareyson's theory of formativity. Thirdly, 
art is not pursued for its own sake, since artworks can open up new possibilities in our everyday life by constantly transforming our habits and our practices upon which we base our daily relation with the world.

\section{On a Certain Latitude of Interpretation. Peirce's Semiotic of Vagueness}

In this section I will focus on Peirce's notion of vagueness. The concept of vagueness is extremely important within Peirce's philosophical system because it does not only concern the logical-communicative aspect of signs, but it is also what allows him to support his theory of fallibilism, synechism and realism, ${ }^{2}$ arguing that reality itself is something general and vague. As a result, vagueness does not only have a mere semiotic value, but also an ontic one. It is an irreducible constituent of reality, "a universal real principle, and not a deficiency of our knowledge" (CP.4.344) because, for instance, vagueness surrounds our acritical forms of certainty like habits, indubitable beliefs and common-sense practices.

Within the pragmatist movement, Peirce is not the only one to discuss the importance of vagueness: William James, in his Principles of Psychology (1890), focuses on this concept as far as it concerns a fruitful discovery for both psychology and philosophy. In the chapter entitled "The Stream of Thought," James describes our mental life as a continuous stream and develops a conception of vagueness by understanding it as an inarticulate background from which knowledge must start. According to James, the aim is not to minimize these vague elements of our knowledge so as to achieve absolute precision and accuracy, but to argue in favor of this vague and inarticulate dimension of experience so as to avoid the static subject-object dichotomy, understanding that vagueness is an unavoidable dimension of experience. Obviously, it will not be possible to give either a full account of this concept or a very detailed explanation; thus, I will set aside these important issues, giving only a sketch to understand the importance of vagueness in relation to the Echian concept of openness.

In 1905 Peirce wrote: "I have worked out the logic of vagueness with something like completeness" (5.506). Both Claudine Tiercelin (1992: 66) and Jarret E. Brock (1969: 3) state that the logic of vagueness is not something new to be discovered in Peirce's published and unpublished writings, but that it deals with the tripartition in Stechiology, Critic and Methodeutic, "which are names for three branches of Peirce's general semiotic" (Brock 1969: 4). The logic of vague is something related to symbols and is just an element of a triad of terms composed of indeterminacy and generality. According to Peirce (CP.4.531), the creation of symbols, which are general and indeterminate signs, is governed by a habit - or, more generally a thirdness - that gives a rule to use and interpret them; in Peirce's semiotics each sign has its own qualitative distinctness and, through its triadic stream of interpretants (emotional, energetical and logical), makes its object present in its own way. Nevertheless, Peirce's account of interpretants ${ }^{3}$ is quite complex, and I will not discuss it here, since Opera Aperta is still part of the pre-Peircean period of Eco's thought. As I mentioned at the beginning of this section, this journey into Peirce's logic of vagueness is useful just to highlight its connection with the qualitative and vague dimension of openness.

8 Peirce begins to research the concept of vagueness when he realizes that no sign is either absolutely determined and precise - otherwise knowledge could not be 
questioned and further explored - or absolutely indeterminate - otherwise knowledge would be meaningless.

A subject is determinate in respect to any character which inheres in it or is (universally and affirmatively) predicated of it, as well as in respect to the negative of such character, these being the very same respect. In all other respects it is indeterminate. (CP.5.447)

9 Subsequently, vagueness runs through and permeates the entire sign-chain and pushes signs to specify themselves further in new interpretations. Peirce, therefore, defines vagueness as something affecting all signs; we can then say that vagueness sheds light on the processual aspect of semiosis and sets it in motion. More specifically, a sign is indeterminate when it allows a latitude of interpretation or determination in its definition, whereas it is determinate when leaving no latitude of interpretation or determination. This latitude can be a matter of intended breadth (reference) or intended depth (meaning). To summarize, the logic of vagueness is the theoretical tool by which Peirce defines the conditions of symbols when they may be said to possess the different kinds of indeterminacy and determinacy in breadth and depth. As Brock specifies (1969: 24), Peirce argues that indefiniteness functions in two ways: the vague nature of signs involves, on the one hand, the relationship between signs and objects and, on the other hand, the relationship between signs and interpretants (CP.4.543, 5.448). This partial indeterminacy that characterizes every sign can be declined in two ways; hence, vagueness and generality are two opposite forms of indeterminacy because one excludes the other. Consequently, if a sign is vague, it cannot be general and vice versa.

Let us now consider Peirce's 1902 definition of "vague" in the Baldwin Dictionary:

Indeterminate in intention. A proposition is vague when there are possible states of things concerning which it is intrinsically uncertain whether, had they been contemplated by the speaker, he would have regarded them as excluded or allowed by the proposition. By intrinsically uncertain we mean not uncertain in consequence of any ignorance of the interpreter, but because the speaker's habits of language were indeterminate; so that one day he would regard the proposition as excluding, another as admitting, those states of things. Yet this must be understood to have reference to what might be deduced from a perfect knowledge of his state of mind; for it is precisely because these questions never did, or did not frequently present themselves that his habit remained indeterminate. (Peirce 1902: 748)

11 A vague sign, then, has a number of possible objects, but the interpretant is limited by the intended object. A general sign has a number of possible interpretants, and its interpretation is not constrained by the object. ${ }^{4}$ Since all symbols are general and vague, indeterminacy is double. There is a restriction put on the interpretant by an indeterminate object - the utterer does not authorize any kind of interpretation - as well as a latitude of interpretation given to the interpretant by a level of absence of restriction from the object. To better understand what Peirce has in mind, we have to look at vagueness as a matter of firstness, strictly bound to the qualitative and immediate potentiality of experience. As we know from Peirce's phaneroscopy, firstness is a potentiality that needs to be embodied and articulated in the effectual reality. Vagueness is an element of possibility dealing with the potentiality of qualities, since to be vague means to be ready for further determinations. Vagueness is then not related to absolute indeterminacy but is something capable of being articulated; possibility and potentiality set in motion the process of articulating an experience which begins from the vague and immediate experience. 


\section{to specify how the interpretative articulation emerges from pre-discursive and vague} levels of experience.

\section{Peirce and Dewey on Qualitative Experience}

I am quite sure that he, above all modern philosophers, has opened the road which permits a truly experiential philosophy to be developed which does not, like traditional empirical philosophies, cut experience off from nature... For this reason, it is important that Peirce's theory should be understood for what it is. (Dewey 1935: 708)

These are the conclusive words of Dewey's Peirce's Theory of Quality, originally published in The Journal of Philosophy in 1935. On this occasion Dewey's aim is not only to show how Peirce develops the concept of quality, but also to make explicit its role, affirming its indispensable importance for an aesthetic theory. As I have already discussed, firstness, according to Peirce's mature phaneroscopy, deals with indeterminacy and possibility: it designates the quality of feelings - such as a color, a sound or a taste - in its perceptive immediacy, without reference to anything else. A quality, which offers a "possibility of sensation" (CP.1.426), is a simple and unrelated positive character, allpervading and wholly possible.

Let us now consider how Dewey deepens his reflection on the notion of quality by placing it in an aesthetic context. In order to do this, it is crucial to refer to Dewey's Art as Experience (1934), which is one of the seminal contributions to a philosophy of art and to its correlation with experience. According to Dewey, an aesthetic experience occurs when an experience, moving from its qualitative and immediate background, develops and proceeds, articulating its aesthetic quality, towards its fulfillment (ibid.: 41). According to Peirce and Dewey, qualities are elements which unify the immediate experience; therefore, this indeterminate background is required for the uniqueness of an experience. Our lived experience is immediately qualitative since qualities are the necessary material to have an experience. Without this unarticulated and indetermined qualitative background, it is not possible to articulate any kind of experience.

In contrast with such experience, we have an experience when the material experienced runs its course to fulfillment. Then and then only is it integrated within and demarcated in the general stream of experience from other experiences. Such an experience is a whole and carries with it its own individualizing quality and self-sufficiency. It is an experience. (Ibid.: 35)

Thus, an experience comes out of a vague and qualitative immediacy and is something well-defined, with a precise beginning and ending. Just as in Peirce vagueness refers to a potential and processual dimension, in the same way the qualitative experience described by Dewey makes it possible to emphasize the dynamic and processual nature of the aesthetic experience, looking at the artworks as bodily interactions between artist and audience, or artists and their environment.

The difference between an aesthetic experience and an intellectual one lies in the fact that the material of art is made up of qualities; the intellectual experience is made up of signs or symbols that do not have an intrinsic quality of their own but stand for objects that can be experienced qualitatively in another experience. Briefly, the intellectual experience is qualitatively mediated by other experiences, whereas the aesthetic 
experience integrates an aesthetic quality towards its fulfilment: this is the quality that provides the basis for naming a given experience as the unique experience it is.

Dewey's thesis is that aesthetics theories run counter to the aesthetic experience, which involves a perceptual continuity of relations and a sequence of raw sensations that can only be found within experience and, specifically, a pre-reflective (nonobjectified) and qualitative experience. ${ }^{5}$ Dewey puts the accent on the dynamic quality of "openness to experience" rather than on a fixed attitude or mindset, thus emphasizing how the continuity of relations requires a non-dualistic approach. Therefore, Dewey gives importance to movement, as through movement one acts in direct response to the world. Movement is then an explicit strategy not to proceed from "mind" to experience, but to perceive the relation between human organisms and world in transactive way. ${ }^{6}$ I must perceive and "feel" my way forward through active engagement with the world, which means that my perception changes according to the objects at hand. In order to explore the quality of openness, I must literally open myself to the physical sensation of vagueness and indeterminacy.

18 The next section places the outcome of the first two in a context that is in some respects wider and in some respects narrower than the one provided by this discussion. Hence, we will see in which respects the poetics of the open work is closer to Dewey and Peirce than to Pareyson.

\section{Eco Between Pareyson and Dewey}

19 Pareyson's Estetica: Teoria della formatività presents an openly anti-Crocian aesthetics. Pareyson's research, as I will discuss in this section, concerns the primacy of the person, both in the formative and in the interpretative process, and does not consider the performer and their interiority as an obstacle to the work of art. Pareyson's aesthetics develops around the concepts of person, form, interpretation and is presented as a systematic theory of formativity.

20 When writing about forms, Pareyson prefers to use the term formativity to avoid the form-matter dualism in which matter is seen as something passive and static and form as an active force printing its shape on an immobile surface. The term formativity highlights the energetic and vital side not only of forms, but also of the matter, underlining the dynamic process of giving shape to something that is already in motion. Matter and form are a living dynamic organism even before the act of interpretation, as "a form, once it has reached completion and autonomy, can be seen as perfect only if it is dynamically considered" (Eco 1989: 163). An artwork makes us aware of new semiosic possibilities and does not train semiosis just at the upper levels, but also at the lower thresholds of experience itself, from which art emerges as the transfiguration of matter into sense.

21 According to Pareyson (1974: 59-61), to form means to do and to do means to invent a new way of doing: when an artist plans to create an artwork, they do not use a predetermined rule or technique but proceed by trial and error, experimenting different possibilities and inventing their proper way to make the artwork. It is necessary to try, attempting procedures and inventing various possibilities that must be tested; as a result, inventiveness, as the capacity of figuring multiples trails, creates an artwork. 

not oriented to a mere realization of a project given at the beginning; rather, it presents itself as an attempt, open as much to success as to failure, as "art is the ability to invent the way of doing things" (Pareyson 1954: 59).

is no way to find the form without looking for a way to do it: forms are in the making. Furthermore, to Pareyson, form and former, as form and matter, are a living organism too, since the formed matter is both the product and the producer of the interpretation: it is created by the artist's interpretation and requires the user's interpretation.

us now move on to the concept of interpretation, another cornerstone in Pareyson's aesthetics. ${ }^{7}$ Works of art require the relation with a performer - a reader, a listener, an observer (Pareyson 1954: 223); the notion of interpretation implies the enjoyment of an artwork, its translation and, more generally, it implies a certain practice by the user. ${ }^{8}$ As a result, the interpretative process has a revelatory character: the interpreter's gesture attempts to discover the artist's intentions (intentio auctoris). There is a phenomenological residue in Pareyson's aesthetic theory whereby individual interpretations highlight different aspects of the same object.

Interpretation is a form of knowing in which, on one side, receptivity and activity are inseparable, and, on the other, the known is a form and the knowers is a person. Without doubts, interpretation is knowledge because to interpret means catching, grasping, understanding and penetrating. (Pareyson 1954: 189)

Works of art are not passive objects that need to be activated by one or multiple acts of interpretation but are already open and directed towards the act of interpretation, challenging the interpreter. In fact, through the concepts of formativity and interpretation, Pareyson emphasizes the dynamic elements both on the level of interpretation and on the level of constitution of the object. Eco borrows from Pareyson the procedural and dynamic aspects of the form and the openness of the work to infinite interpretative perspectives but, contrariwise Eco, following Dewey, argues that the interpretative process has a productive and creative value.

This is the reason why Eco defines the open work as a work in motion: the quality of openness comes to bear on the direct experience of form-giving, articulating its vague and indeterminate elements. According to Dewey, furthermore, the open work promotes a new way of understanding the relationship between contemplation and interpretation of works of art and, consequently, a new way of understanding the relationship between the artist and their audience.

Dewey offers us a transactional conception of knowledge that becomes particularly suggestive when set side by side with his definition of the aesthetic object. The work of art, for him, is the fruit of a process of organization whereby personal experiences, facts, values, meanings are incorporated into a particular material and become one with it. (Eco 1989: 27)

According to the poetics of the open work, to make our ideas clear means to entrust the qualitative potentiality of an open work to the infinite interpretations of the performer. The notion of vagueness allows for the understanding of openness by emphasizing the primacy of interpretative practices rather than the representational aspect of the artwork. Art is in the experience rather than in the objects: to interpret a work of art is not to "represent" it, but to open oneself to its demands of presentation. 
Art is formative just as life is formative: it is open, revealing its intrinsic productive processes to anyone who is attentive.

By openness, Eco means a potential and vague conglomerate of possible interpretations which can be actualized and articulated by the performer. The performance is, therefore, a necessary and constitutive aspect of the reading of a work of art, as it is an innate and irrepressible aspect of its own formation. It is claimed and desired by the work because it was already contained in the process that formed it. The fulfilment of the aesthetic qualities of an open work lies not only in the hands of the author but also in the performer's.

To clarify a sign - in this case a product of art - means to follow its movement by practicing it in every possible way; there is no stimulus-response relationship in the interpretation of a text, but a repetition of form, which is not understood as an eternal and immutable idea but as power, as formativity, as a transit of interpretations. The open work starts the semiosic process, the trirelative force that cannot be reduced to a dyadic relation, or, as Peirce said, the "action, or influence, which is, or involves, a cooperation of three subjects, such as a sign, its object, and its interpretant, this trirelative influence not being in any way resolvable into actions between pairs" (EP. 2.411). The vitality of an open work lives in that vague and indeterminate gap that introduces a third element between the reader and the work.

To this extent, ambiguity is not an accessory to the message: it is its fundamental feature. This is what forces the addressee to approach the message in a different fashion, not to use it as a mere vehicle. (Eco 1989: 196)

Vagueness characterizes the work in its openness and allows the work of art to be open to different interpretations. The author himself offers the performer an unfinished work: they do not know exactly how the work will be. Moreover, vagueness - what Dewey calls the qualitative level of the experience - can function, according to Eco, as a sort of introduction to the aesthetic experience, because it stimulates an interpretive effort, a process that attempts to articulate the qualitative and indeterminate openness of the experience to its own fulfillment.

31 The aesthetics of openness, however, is a type of aesthetics of vagueness that is congruent with a pragmatist account and goes against an essentialist vision, as it will later become clearer in Eco's writings on the concept of encyclopedia. The open work is an organism composed of interconnected pluralities and without clear boundaries. Movements make the form and form moves, becomes, evolves: it is itself form-making. The open work, like the body of a dancer, is formed through the indeterminate movement of the interpretations that stage it. We can then say that the aesthetic experience - according to both Dewey and Eco - puts emphasis on the creative character of action. This has profound implications for a creative action and a sense of "self," since it advances the role of subjectivity and the ability to make nondeterminate choices, which is an essential component of the making of anything creative, not only for the artist but also for the performer and interpreter. On the contrary, according to Pareyson, in order to aesthetically appreciate the sensitive qualities of an object of art, we must already know that the object is a work of art: between an object which is a work of art and one that is not, there can be differences that cannot be considered perceptive differences.

32 It is not, then, the aesthetic experience which allows us to decide what is or what is not a work of art, but rather an interpretive act: this is the reason why Eco is closer to the 
qualitative thought of Peirce and Dewey than to Pareysonian hermeneutics. The interpretative act is such because it emerges from a vague and qualitative background. Opera Aperta puts the accent on the fact that to have an experience - or interpreting an artwork - means to articulate a pervasive, qualitative and indeterminate level of experience in its own aesthetic quality. In conclusion, Pareyson's theory of formativity is still extensively linked to a phenomenology of the person, with the consequence that it is the hermeneutic act that distinguishes what is art and what is not.

\section{More Vagueness, More Information}

In the previous section I have analyzed how contemporary poetics requires a particular autonomous commitment of the user, often a reconstruction of the proposed material in which there is no univocal and necessary sequence of events, but a field of probability and a vagueness of possibility that stimulate interpretative practices. Therefore, openness and vagueness are the conditions of every aesthetic fruition despite the fact that the artist aims at univocal and clear communication - since vagueness precedes interpretation and makes it possible. The open work is a concept fully consonant with a pragmatist aesthetics, which considers artworks and the aesthetic dimensions of experience as dynamically directed towards a pluralistic universe of possible interpretations.

This transformative power of the aesthetic message could be defined as an increase and multiplication of the possible meanings of an artistic message. According to Eco, however, the term may lead to misunderstandings, because it is hard to speak of "meaning" when analyzing the type of communication provided by an open work. For this reason, in Opera Aperta, Eco chooses to stress the concept of information in relation to those of openness and vagueness. As Claudio Paolucci states, according to Eco,

we cannot understand the domain of art if we do not go beyond the domain of art itself and see what scientists do within the domains of physics and mathematics. We cannot understand the new avant-garde art unless we go beyond the domain of art and try to understand concepts such as "disorder" and "entropy" and "code," which come from the theory of information. (Paolucci 2017: 54)

Hence, the poetics of openness implies the search for a source of possible messages endowed with a certain disorder but tries to reach this condition without losing the transmission of an ordered message. As stated by Robert E. Innis (2018), vagueness and openness are necessary but not sufficient conditions to define an open work. Furthermore, Eco states that the ambiguity of signs in an artwork cannot be separated from their aesthetic organization: the two are mutually supportive and motivating, since art articulates the qualitative continuum of the experience, considering multiple aspects of the human life (emotional, intellectual, axiological).

What interests Eco about this theory, in brief, is the principle that the information (as opposed to the "meaning") of a message is in inverse proportion to its probability or predictability. This suggests to him a parallel between the concept of information and the effect of art, particularly modern art, since the forms of art can be said to possess a high degree of improbability or unpredictability by virtue of their contravention of established conventions of expression. Thus, Eco argues, art in general may be seen as conveying a much higher degree of information, though not necessarily a higher degree of meaning, than more conventional kinds of communication; and the modern open work may be seen as conveying an 
exceptionally high degree of information, because of the radical contraventions of

established conventions that characterize it. (Eco 1989: x-xi) calculate the quantity of information contained in a particular message" and that "information is, therefore, an additive quantity, something that is added to what one already knows as if it were an original acquisition" (1989: 45). The information theory argues that a message produces more information only if it says something totally different from the information heritage already available to the community. In short, it is necessary to introduce an element of novelty and disorder to create new forms of knowledge that will sooner or later become stable habits of the community. As Innis (2018) perfectly sums up, "disorder in communication is disorder, then, only in relation to a previous order" and "order introduces disorder in order to introduce new forms of order." Now, without dwelling on mathematics and cybernetics, to better understand this aspect of information theory, let us focus on two literary cases quoted by Eco, which make clear how different degrees of vagueness, openness and disorder create new interpretative perspectives. The first one is from Dante, the second from Joyce, a writer Eco considered particularly interesting.

O Light Eternal, who alone abidest in Thyself,

alone knowest Thyself, and known to Thyself

and knowing, lovest and smilest on Thyself! (Eco 1989: 40)

Dante offers the reader a limited, low-order openness, describing a univocal object with univocal signs. He represents a predetermined and necessary cosmos in which each perspective gives back the same vision: the various parts are indeed only the exact reproduction of the whole. There is no space for incomprehensibility or for misreading, because there is nothing vague. As Eco said, "the order of a work of art in this period is a mirror of imperial and theocratic society" (ibid.: 6).

From quiqui quinet to michemiche chelet and a jambe-batiste to a brulobrulo! It is told in sounds in utter that, in signs so adds to, in universal, in polygluttural, in each ausiliary neutral idiom, sordomutics, florilingua, sheltafocal, flayflutter, a con's cu-bane, a pro's tutute, strassarab, ereperse and anythongue athall. (Ibid.: 41)

Joyce, on the other hand, offers the reader a work to finish, a game of sounds that one must try to frame in order to build a unified vision of the cosmos. The disorder of signs, the use of metaphors and the explosion of figures incite the viewer to create their own network of connections. He introduces "forms of organized disorder into a system to increase its capacity to convey information" (ibid.: 60). Joyce offers the reader an image of the ontological situation of the contemporary world: each interpretive response is configured as a slit that divides the chaosmotic continuum of the text, giving back its own vision and particular perspective. Joyce creates a message that is multifaceted in itself and thanks to the form it has taken. Nevertheless, there is no strict difference in meaning, as both Dante and Joyce try to describe the universe. Therefore, in the second example, the originality of organization, the unpredictability concerning a probability system and the disorganization which enters it are the only elements to have caused a growth in information. The disorder appears to be such solely because it starts from a pre-existing order.

In standard communication the undefined and vague elements must be reduced to a minimum and the message must be clear and intelligible: the non-aesthetic message is sluggish and discursive, and it is not articulated as a developing movement towards its own fulfilment. In the aesthetic message, contrariwise, disorder and fuzzy boundaries

European Journal of Pragmatism and American Philosophy, XIII-1 | 2021 
contribute to increase the informative potentiality and to articulate the aesthetic quality, opening it to various interpretations. The difference between Dante's poetics and Joyce's lies in the fact that while the poetics of the former contravenes the order according to very precise limits, the poetics of the latter inserts innumerable entropic motifs and disorderly aspects. Consequently, the new order that is born out of it will be much more unexpected than the original one: the more unpredictable and plurivocal the structure becomes, the more the information increases.

\section{Use or Interpretation? Vagueness in Context}

In the previous sections I examined how openness and vagueness contribute to define an open work and to articulate the aesthetic message that it conveys. Then, I have outlined the role of vagueness - on which the poetics of openness is grounded - as a potential increase in information due to the insertion of entropic motifs and elements of disorder that reformulate the pre-existing order into new possibilities of order. The dialectics of the open work - its form a dynamic possibility of multiple meanings takes place in the oscillation between standard communication and pure indeterminacy. An open work is shot through with vagueness and indeterminacy, which are not to be understood as "the checkmate of every ordering possibility but as fertile disorder of which modern culture has shown us the positivity" (Eco 1962: 1).

41 The aim of this section is to distinguish the free use of a text from its interpretation. It is first necessary to briefly consider the limits of the semiotic process in order to understand its practical effects. It is important to notice that the interpretative freedom - offered to the reader by the author - has to be supervised by formal coordinates which are open to the free choices of the users. Here "vague" means open to different possible interpretations, which only a contextual practice can determine. According to Eco, contextuality, as it is the absence of any kind of essentialism, allows the author to limit the interpretation using different strategies.

If it is true that the concept of vagueness plays an important role in defining the concept of an open work, and if it is true that its aesthetic message, in virtue of the vague form that shapes it, helps to take into consideration the interpretation of the work, it is necessary, however, to avoid the free use of a text, outlining the limits of the interpretative process and the role of the reader. That is the reason why Eco, in the introduction to Lector in Fabula, wrote that it is important to find "a way to consider the reader but, at the same time, to limit and control it." In the third section of this paper, after a brief account of Peirce's notion of vagueness and Dewey's concept of quality, I analyzed how to read a text means to actualize and to articulate a vague tangle of potentialities. The text needs a reader as a communicative potential, as the life of a text is outside the text itself, in the different interpretative acts that actualize it. In Lector in Fabula, Eco adds that this step is necessary because open texts, more than the closed ones, are incomplete for two reasons: the first reason is that each message requires a grammatical competence on the part of the writer; the second one is that the aim of a text is to leave the interpretative initiative to the reader. A text, more decisively than any other message, requires active and conscious cooperative movements from the reader. The work of interpretation, however, imposes the choice of limits, the delimitation of interpretative directions and the design of universes of discourse. On 
this matter, Eco introduces a fundamental notion for the reader to understand what he (Eco) means when he writes about "limiting the universe of discourse."

The concept of a model reader is nothing more than a strategy that the author implements to limit the possible interpretations of a text. To postulate a model reader is to outline the conditions of interpretability of a text. To explain how this strategy work, I must refer to its chiasmic structure. The notion of model reader brings with it three other elements necessary to articulate this strategy: the empirical reader, the empirical author and the model author. As a consequence of this chiasmic structure, on the one hand the empirical author presupposes a model reader, while, on the other hand, the empirical reader presupposes a model author (Eco 1978: 62). Eco explains that "presupposing" does not only mean hypothesizing but also producing a model reader, moving the text in such a way as to constitute them. When an empirical author decides to write a text, they must take into consideration the addressees of the text, thus outlining a sort of interpretative map. This map allows some paths and forbids others. In turn, the empirical reader, reading the text, will be led to recognize, behind the writing of the text, a model author, of whom they have no direct knowledge and whose generative process they must understand. If an author decides to provide the reader with a rather complex and cross-referenced interpretative map, such a map will be more open to different interpretations because the high degree of vagueness fragments the univocal meaning of a text. If, on the contrary, the map with which the author provides their reader has a unique direction, then the reader will have a lower chance of misinterpreting a text. For this reason, the reader of a "closed" text will be more inclined to force it into meaning what they want.

What limits the interpretation of a text is therefore determined by the strategy that the author chooses to implement, restricting, to a greater or lesser extent, the universe of discourse of a text. Following the different possibilities of a text, within a given discourse universe, means interpreting a text; enlarging the discourse universe, not taking into account the author's intentions, means using a text. Open and vague texts require model readers of a different nature, whereas closed and precise texts reduce the spectrum of possible readers. If a text is constructed in such a way as to have a vaguer universe of discourse, then the reader will not feel the need to widen its boundaries.

I tried to show that the notion of unlimited semiosis does not lead to the conclusion that interpretation has no criteria. To say that interpretation is potentially unlimited does not mean that interpretation has no object and that it "riverruns" merely for its own sake. To say that a text has potentially no end does not mean that every act of interpretation can have a happy end. (Eco 1992: 23-4)

Thus, Eco claims that there is nothing more open than a closed text but, in this case, openness does not mean that the text is open to various interpretations, but only that it allows for a free use by the reader. In this regard, Eco brings a clear example of a free use of a text: Les Mystères de Paris by Sue. Even if this text has a different purpose, it was interpreted in a proletarian way. ${ }^{9}$ The extreme openness of a closed text often translates into violence, into a use that is partial and unwanted by the author: it is an act of violence rather than an act of cooperation between author and reader. A text that postulates only one type of reader, will be more likely to become another book, as happened to Les Mystères de Paris.

Universes of discourse and the strategy of the model reader create the possibility of interpreting texts, the communicative conditions to which they are subject, the 
assurance of a communicative relationship that does not degenerate into chaos, the tension within a mass of information made intentionally available to the user and a guaranteed minimum of comprehension - the encounter between the will of the author and the reader's response.

Any other decision to use a text freely corresponds to the decision to enlarge the universe of discourse. The dynamic of unlimited semiosis does not prohibit it, but rather encourages it. But you need to know whether you want to practice semiosis or interpret a text. (Eco 1978: 66; my translation)

So, going back to the first lines of this paper, it can be noted then that Peirce's notion of vagueness - as Eco's concept of openness - works twice as a surplus: a surplus of signification, diffused at the level of the unlimited cross-reference of semiosis, as we saw in the previous section; and a surplus of action, never confined to a single univocal rule, but which always foresees its variation and determination. The poetics of the open work sheds light on the fact that meanings and situations can be vague and undefined, and they can be left partially indeterminate as long as such indeterminacy allows us to continue our inquiry. As a result, Eco notices that all interpretation takes place in a context of communication: it is finally not important that some predicates should suffer from logico-semantical indeterminacy, providing that the context is there to help us specify our knowledge, which involves our acritical beliefs and the habits upon which we build our relation with the world.

In other words, the essence of the open work does not lie in the absence of meaning but rather in its multiplicity, since artworks represent an attempt at creating new meanings and alternative possibilities, which, if accepted by society as a whole, enrich our common daily practices. In conclusion, according to Eco, art has a transformative, pragmatic and instrumental power, since to create and to interpret artworks means to change the ways in which practices and habits transform the world, enhancing the development of the human organism with its environment.

\section{BIBLIOGRAPHY}

BROCK Jarret E., (1969), C.S. Peirce's Logic of Vagueness, Ph.D. dissertation, University of Illinois.

DE MALLAC G., (1971), “The Poetics of the Open Form: Umberto Eco's Notion of Opera Aperta,” Books Abroad, 45 (1), 31-6.

DEWEY John, (1934), Art as Experience, New York, Capricorn Books, G. P. Putnam's Sons.

DEWEY John, (1935), “Peirce's Theory of Quality,” The Journal of Philosophy, 32 (26), 701-8.

ECO Umberto, (1962/1989), Opera Aperta. Forma e indeterminazione nelle poetiche contemporanee, Milan, Bompiani, The Open Work, trans. by Anna Cancogni, introduction by David Robey, Cambridge, Mass., Harvard University Press.

ECO Umberto, (1975), A Theory of Semiotics, Bloomington, Indiana University Press.

ECo Umberto, (1978), Lector in fabula, Milan, Bompiani. 
ECO Umberto, (1979), The Role of the Reader. Explorations in the Semiotics of Text, Bloomington, Indiana University Press.

ECO Umberto, (1992), Interpretation and Overinterpretation, Cambridge, Cambridge University Press. ECo Umberto, (2017), "Intellectual Autobiography," in Randall E. Auxier \& Sara G. Beardsworth (eds), The Library of Living Philosophers, volume 35, The Philosophy of Umberto Eco, Chicago, Il., Open Court, 27-101.

FABBRICHESI Rossella, (2001), Continuità e vaghezza. Leibniz, Goethe, Peirce, Wittgenstein, Milan, Librerie Cuem.

INNIS Robert E., (2018), “The Lost Trail of Dewey. Eco's Problematic Debt to Pragmatism,” European Journal of Pragmatism and American Philosophy, X, 1. Online: (https://journals.openedition.org/ ejpap/1159).

NADIN Mihai, (1980) "The Logic of Vagueness and the Category of Synechism," The Relevance of Charles Peirce, 63 (3), 351-63.

olIVA Stefano, (2018), "Risonanze della Teoria della Formatività di Luigi Pareyson nell’Estetica Musicale Contemporanea," Rivista Portuguesa de Filosofia, 74 (4), 1077-92.

PAREYSON Luigi, (1954), Estetica: Teoria della formatività, Turin, Edizioni di filosofia.

PAOLUCCI Claudio, (2017), Tra ordine e avventura, Milan, Feltrinelli.

PEIRCE Charles Sanders, (1902), "Vague (in logic)," Dictionary of Philosophy and Psychology, Vol. II, J. M. Baldwin (ed.), London, Macmillan and Co, 748.

PEIRCE Charles Sanders, (1931-1935), Collected Papers of Charles Sanders Peirce, vol. 1-6, C.

Hartshorne, P. Weiss, eds, Cambridge, Mass., Harvard University Press (CP).

PEIRCE Charles Sanders, (1992-1998), The Essential Peirce. Selected Philosophical Writings, v. 2: 1893-1913, ed. by The Peirce Edition Project, Bloomington, Indiana University Press (EP).

TIERCELIN Claudine, (1992), "Vagueness and the Unity of C. S. Peirce's Realism," Transactions of Charles S. Peirce Society, 28 (1), 51-82.

\section{NOTES}

1. "At the same time, I was interested in the study of aesthetics and, naturally, all beginners had to read the idealist philosopher Benedetto Croce. Even at that time I was beginning to think that Croce had not understood much about art, and in that sense, I was rebelling against contemporary Italian culture, which still lay within the idealist camp. This was the reason why, in order to elude the influence of German idealist philosophers, who were mandatory reading for all Italian philosophy students, I (like many others of my generation) went in for French and Anglo-American philosophy. In my university years reading Dewey's Art as Experience was a liberation for me," Eco (2017: 30-1).

2. For a close examination of these issues, see Nadin 1980, Tiercelin 1992 and Fabbrichesi 2001.

3. According to Peirce, there are different kind of interpretants. The first one is immediate and "includes feelings; for there must, at least, be a sense of comprehending." On the second one, called energetic, Pierce says that "if it includes more than mere feeling, it must evoke some kind of effort." The third interpretant is logical or final and deals with a habit of action (EP.2.409).

4. In the final section, we will see how this "restriction of interpretation" could be interpreted in Eco's terms and how this restriction plays a fundamental role in distinguishing between using 
(and so overinterpreting) and interpreting an open work. In this sense, an open work does not authorize any kind of interpretation because vagueness works as a context dependent notion.

5. 'Dewey is perfectly aware of the fact that the 'dim' and the 'vague' of a primary experience which always precede the categorical rigidity imposed on us by reflection - are aspects of its global nature," Eco (1989: 26).

6. "In spite of the elliptical character of Keats' statements two points emerge. One of them is his conviction that 'reasonings' have an origin like that of the movements of a wild creature toward its goal, and they may become spontaneous, 'instinctive,' and when they become instinctive are sensuous and immediate, poetic. The other side of this conviction is his belief that no 'reasoning' as reasoning, that is, as excluding imagination and sense, can reach truth. Even 'the greatest philosopher' exercises an animal-like preference to guide his thinking to its conclusions," (Dewey 1934: 33).

7. “Referring to Pareyson's aesthetics, Eco notes how a certain openness is typical of all art, since the form always challenges the interpreter, whose point of view constitutes a concrete personal perspective on the work itself. On the other hand, the poetics that make this instance its own identifies openness as the fundamental aspect of contemporary art," (Oliva 2018: 1085).

8. In Eco's reformulation, the general conditions of the interpretative process are taken up in the open work as a precise poetic program, reshaping the relationship between work and performance and inviting the interpreter and the user to a participatory and active attitude.

9. “This was the case of Sue's Les Mystères de Paris, which, written initially in a dandyish mood to please cultivated readers, aroused as a result a passionate process of identification on the part of an illiterate audience: when, on the contrary, it was written to educate such a 'dangerous' audience to a moderate vision of social harmony, it produced as a side effect a revolutionary uprising," (Eco 1979: 8).

\section{ABSTRACTS}

In this essay I will discuss the issue of vagueness when defining the concept of open work within the philosophy of Umberto Eco (1932-2016), particularly considering its relevance for the development of his original semiotic view. The analysis of vagueness allows us to stress the importance of Eco's concept of open work not only in Opera Aperta (1962) but in different phases of his thought. This paper is divided into five sections. Section 1 briefly outlines the Peircean notion of vagueness, trying to understand it as a pivotal concept to define the structure and dynamical form of the open work. Section 2 dwells on the concept of quality in both John Dewey and Charles Sanders Peirce: here the possibility of articulating an interpretation is considered embodied in the vague immediacy of the qualitative experience. Section 3 analyses to what extent an artwork can be considered open and in motion, according to the Pareysonian concepts of form and interpretation. Section 4 stresses the hypothesis that vagueness produces not only the condition of possibility of an open work and of its multiple interpretations, but also an increase of information due to its aesthetic quality. Section 5 calls into question the distinction between use and interpretation and specifies that interpreting an open work does not mean using it for your own purposes but interpreting a developmental movement towards its own fulfilment; a text is nothing other than the rule that constitutes the universe of its interpretations. 
AUTHOR

ROCCO MONTI

Università degli Studi di Milano

monti.rocco9[at]gmail.com 